\title{
How the Attitude of Acceptance, Enthusiasm and Learning through Motivation Affects Brain Development in Children with Autism: A Literature Review
}

\author{
Joana Prata ${ }^{1,2,}$, Rui Coelho ${ }^{1,2}$ and Wenn Lawson ${ }^{3}$ \\ ${ }^{1}$ Departamento de Neurociências Clínicas e Saúde Mental, Faculdade de Medicina da Universidade do \\ Porto, Portugal \\ ${ }^{2}$ i3s - Instituto de Investigação e Inovação em Saúde, Portugal \\ ${ }^{3}$ Autism Cooperative Research Center, Long Pocket Campus, University of Queensland, Australia
}

\begin{abstract}
Research on the autism spectrum (AS) has expanded tremendously over the last two decades with exciting insights into underlying neurobiology. Neuroplasticity, the remarkable ability of the brain to form new connections as a result of experience, is not limited to specific parts of the brain nor does it have a time limit meaning that growth and learning are on-going processes. In this review we explore the impact of the attitude of acceptance, enthusiasm and learning through motivation on brain development in children on the AS. The first part of the review focusses on the impact of attitude on social, emotional and cognitive development, while the second part focusses on the impact of attitude on brain biology.
\end{abstract}

Keywords: Autism, attitude, acceptance, enthusiasm, motivation, neurobiology.

\section{INTRODUCTION}

Autism is a neurodevelopmental condition with biological, genetic, environmental and developmental causes which are still not clearly understood. Children on the autism spectrum (AS) face challenges that arise from their difficulty in understanding social behavior and interaction, difficulty in understanding and effectively using communication, and difficulty with having reduced flexibility of thought and behavior [1]. One of the most significant aspects of the AS is clinical diversity with most children presenting challenges (to a greater or lesser extent) in these areas. Many also experience sensory perceptual differences which impact the way they relate to people and the world around them [2]. Due to its developmental disposition, the impact of the AS varies throughout life and the same individual may present fluctuating capacity on a daily basis [3]. However, a mere focus on impairments would negate the remarkable abilities that some individuals have, whether a result of genetics, personality, environment or the interaction between them.

Many intervention approaches are currently available for children on the AS. These vary considerably in theoretical background and only a small proportion has scientific evidence of efficacy. Even

*Address correspondence to this author at the Departamento de Neurociências Clínicas e Saúde Mental, Faculdade de Medicina da Universidade do Porto, Alameda Prof. Hernâni Monteiro, 4200-319 Porto, Portugal;

Tel: +351225513674; E-mail: psiquiatria@med.up.pt though early intensive interventions are recommended as treatment of choice, evidence suggests that these programs are not equally beneficial for all children [4]. How a child responds to intervention over time depends on numerous variables and complex interactions between such variables, some of which are related to the child's characteristics but also to the child's environment $[5,6]$. Research on the AS has expanded tremendously over the last two decades and exciting insights to underlying neurobiology challenge traditional theories regarding the AS [7-9]. In this review we suggest that these findings should be considered (in intervention, educational and family settings) to help individuals achieve their full potential.

Children on the AS have a very unique way of experiencing the world and face challenges in day to day events which they find difficult to process and make sense of. The attitude that surrounds the child is crucial for the child to overcome challenges [10] and by attitude we refer to three fundamental aspects which we consider essential to invite connection and growth: acceptance, enthusiasm and learning through motivation. In this paper we explore why these aspects of attitude affect brain development in children on the AS hoping not only to increase insight into the individual child but sensitize practitioners and parents regarding the importance of attitude.

The following review explores the impact of attitude on brain development in children on the AS and is divided into two parts. The first presents data regarding 
the impact of the attitude of acceptance, enthusiasm and learning through motivation on social, emotional and cognitive development. The second part focusses on the impact of attitude on brain biology.

\section{ATTITUDE AS FUNDAMENTAL FOR CONNECTION AND DEVELOPMENT}

Attitude can be defined as the way one thinks, feels and behaves about something which reflects a state of mind or disposition. The attitude that surrounds the child on the AS has an enormous impact on how responsive the child will be [10]. A positive attitude is one of acceptance, appreciation and enjoyment of the child and the animated expression of such [10]. Parents observe their children through a filter of conscious and unconscious thoughts, beliefs, and attitudes, which influence the way they perceive their children's actions [11]. When these thoughts are benign they will usually lead to positive actions [11]. However, when they are distressing, they can lead to negative emotions and attributions and impair effective parenting [11].

Neural plasticity is 'an intrinsic property of the brain' and refers to the ability of neurobiology to be altered by experiences [12]. It is the ability of the brain to reorganize itself and gain new skills by forming new neural connections $[13,14]$. Neural plasticity is not an occasional state of the brain meaning that learning can take place throughout a lifetime [12]. However, periods where neural circuits are particularly sensitive to environmental experiences are known as sensitive periods [5]. Sensitive periods are moments of increased plasticity where environmental stimuli have the potential to exert large influences [5]. According to Knudsen (2004) [15], environmental input that takes place during sensitive periods lays the foundation for future learning. Further, experiences that take place during development can serve as strong cues to the system of how the world operates, and can exert a large influence on the construction of the system itself [5]. In other words, if the environment is enriched and favourable, neurobiology will optimize for growth and advancement. On the other hand, if the environment is tough, then neurobiology will optimize for thrift and adversity [5].

Even though sensitive periods are more challenging to identify in emotional domains, we now know that the nature of care provided (for example, how sensitive the caregiver is to the child's needs) influences the quality of the attachment relationship and consequently the individual's emotional health [5]. Research on the mechanisms that underlie the connection between early environment and children's emotional development suggest that parents are critical partly because of the pronounced regulatory effect they have on children's behaviour, physiology and stress reactivity [6]. Specifically, studies have shown that parents can up- and down- regulate the child's emotional expressions of fear depending on their own emotional output [16]; that infants and mothers exhibit similar fluctuations in cortisol patterns throughout the day [17]; that the presence of a parent can influence the child's performance on an affect regulation task by increasing levels on inhibitory control [18] and inhibit the acquisition of conditioned fears [19]; and finally, that access to a caregiver can regulate the hormonal response to stress [20].

Acceptance can be defined as a non-judgment, meaning that the child or his behaviours are not labelled with value judgments (as good or bad, right or wrong). This is not a passive resignation to the child's condition but rather a first step to encourage the child to further develop [10]. According to Baniel (2012) [13], it is essential that one starts where the child is at the present moment regarding what the child can do. Only then can the child connect with what s/he is doing, as well as to their own self, making sense of the experience and progressing beyond present limitations. Mesurado and Richaud (2013) [21] stated that children who believed their parents were accepting, had high levels of extraversion, agreeableness, conscientiousness and openness to experience.

An attitude of acceptance and appreciation for the child will allow parents to maintain a consistently responsive style of interaction [10]. Parenting styles relate to a number of variables including parental emotional state, beliefs and values, educational level and also characteristics of the child [22]. Responsive interaction is the ability to recognize and respond to the child's cues by providing emotional and affective support [22]. It is a type of parental behaviour that responds contingently to the child's cues, follows the child's lead and provides input and support that builds on the child's focus of attention and activity [23]. Responsiveness creates an environment that focuses on responding to children's social behaviour across domains including play, communication, affect and joint attention, thereby providing children with the opportunity to both drive the interaction and practise initiating important social behaviours [24]. 
A meta-analysis by Trivette (2003) [25] concluded that responsive interaction positively influenced cognitive, social and emotional development in children with, or at risk of, developmental disabilities. Responsiveness and affect have been associated with increases in language development, social competence, joint attention and self-regulation [26]; with the child's level of engagement [27], and with higher levels of communication in children on the AS [28]. More recently, Patterson et al., (2014) [24] found that parent responsiveness was associated with childinitiated joint interaction which, in turn, was correlated with desirable social behaviours such as increased affect, attention, interest, and joint attention skills (including coordinated gaze and gestures).

The impact of responsivity on development possibly results from a contingent chain of events where the child signals a need, state or interest, to which the parent responds quickly, sensitively and positively, resulting in the child experiencing their needs met in what, over time, becomes a highly predictable transaction [22]. A possible explanation could be that responsive interaction facilitates the child's feelings of control and self-efficacy, contributing to the child's sense of competence and likelihood of engaging in subsequent interactions and learning situations [29].

Research on more specific cognitions shows that when parents look for reasons why both they and their child act in a particular way, parenting becomes more efficient [11]. On the other hand, when cognitions lead to feelings of anger or depression, these can interfere with effective parenting making it more difficult for parents to react in effective and appropriate ways to the challenges of socialization [30]. Other aspects such as the ability to understand the perspective of the child is also important. Vinik et al., 2012 [31], refer that mothers who recognize what is distressing for their children have children who are better able to cope with their own distress, and Hastings et al., (1997) [32] had previously shown that parents who can accurately identify their children's thoughts and feelings during conflicts are better able to achieve satisfactory outcomes for those conflicts.

An attitude of enthusiasm, as termed in this paper, refers to the ability to be excited or enthusiastic with every effort the child makes. According to Baniel (2012) [13] enthusiasm as a skill is the ability and willingness to acknowledge as important the smallest of changes that occur in the child, to experience joy and internally celebrate those events or actions. Baniel (2012) [13] considers that when we amplify our enthusiasm the child feels it and is able to notice and feel differences within him/her self [33]. The adult's participation in that excitement aids this process in the child's brain [13]. When a child does something new and is excited about it, his spontaneous excitement helps the brain pay attention to and select the relevant neural connections that are being created at that particular moment. As a result, connections are 'grooved in' more clearly and powerfully, becoming available for future use [13]. The brain's ability to perceive differences and create new connections between brain cells is called differentiation. Differentiation allows the child's brain to grow and change, creating complex patterns which enables the child to move and act in ways that are intentional, fluid, accurate and effective [13]. In a study by Matsudaira et al., 2016 [34], parental praise was positively correlated with the personality traits of conscientiousness and openness to experience.

Motivation is the engine of growth and the largest factor in the child's learning and progress [10]. If a child is following his own interests and motivations, learning occurs at a faster rate [10]. According to LeDoux (2002) [35] certain conditions are necessary for learning to occur, namely, a sufficient level of arousal (physiological, biochemical and psychological). Emotions play a key role in arousal and affect communication between brain cells, increasing or decreasing synaptic sensitivity and transmission [36]. Emotions also influence attention, which is necessary for learning. Interest appears to be necessary for learning to occur and animal studies have shown that motivation and engagement synchronize the whole brain, helping the animal organize itself better [13]. According to Lawson (2013) [37], it is possible that individuals on the AS can widen their attention window due to increased gamma synchrony across neuronal networks that are accessed through motivation. When an activity, thought or process is attached to an area of interest, it triggers gamma activity which is thought to enable cognitive processes involved in attention and memory (attention is captured, interest is held and learning occurs) [37].

Prizant (2015) [38], refers to the interests of individuals on the AS as, 'enthusiasms'. When an individual on the AS develops an interest, it should be assumed that the particular subject of interest is a good match for the individual's neurophysiology, has an important function and can be the basis for building relationships and trust [38]. Research has shown that when others first join an individual on the AS in their 
interest, s/he is more likely to be able to shift their attention to join with the other person $[39,40]$. Also, the interest can be used as a way to build connection and as a bridge to other interests [3, 41]. Other authors have also reported on the importance of using interest (which is tied to attention) to accomplish extraordinary things [42-44].

Lawson [45] proposes a theory for explaining the AS called single attention and associated cognition in autism (SAACA). SAACA suggests that the AS is a different learning style which derives from a particular brain configuration, and presents as a result of an attention, interest, sensory-motor perception loop. SAACA suggests that individuals on the AS have a monotropic disposition, meaning that they are only able to focus on one thing at a time as long it is within their interest, and that this is the brain's default setting [3]. It also suggests that use of the individual's interest is key to access learning because that's where attention lies, emphasizing the importance of using the interests of the child on the AS. In other words, motivation/interest in individuals on the AS awakens attention thus creating a neuro-pathway to learning [37]. Attention differences could therefore explain a variety of reactions and behaviors of the individual on the AS. On the other hand, in neuro-typical development the default learning style involves the ability to divide attention between different things, while being able to accommodate many channels of information at any given moment [3].

SAACA challenges traditional cognitive theories of the AS by proposing interest and attention as fundamental to access learning. Theory of mind (ToM) is the ability to attribute independent mental states to self and others, understanding that others have beliefs, perspectives or intentions that differ from one's own [46]. Lack of ToM was proposed by Baron-Cohen et al. (1985) [47] to explain the AS. Lawson (2011) [48] and others have challenged this idea because individuals on the AS are able to pass ToM tests [49, 50], poor ToM is present in other populations [51], neuro-typical children can develop ToM at different rates [52], and ToM may be learned differently in individuals on the AS when compared to neuro-typical development [3, 40]. In fact, evidence suggests that problems with ToM might be the result of other difficulties and not the cause [3]. Executive functioning theory (EF) describes the ability to plan, organize, prioritize and implement the functions an organism needs to think and do, in an appropriate way, and deficits in EF have been implicated in AS [53, 54]. Robins et al., (2004) [55] findings' that individuals on the AS passed Executive Functioning tests when interest was engaged from the individual's perspective, adds to the idea presented by Lawson. The weak central coherence theory (WCC) [56], the difficulty in using global processing of information to form an overall cohesive picture, also fails to consider that individuals on the AS have a particular way of attending to stimulus and that attention is tightly linked to interest [3, 48]. Finally, enhanced perceptual function (EPF) [57], suggests that over-functioning and enhanced perception leads to abilities in particular areas, explaining why individuals on the AS can outperform typical individuals in some domains. EPF draws away from the idea of deficit to the idea of enhancement or hyper-developed and even though it connects attention to perception, it fails to connect interest to this concept [3]. As far as ToM, EF and WCC are concerned, Blakemore and Choudhury (2006) [58], found that the typically developing brain grows into these qualities, and that factors such as age, developmental stage and external and personal factors influence how well individuals perform on tests.

lindividuals on the AS can react to unpredictable change occurring in their environment by feeling stressed, anxious or overwhelmed. This might arise from a dysfunction in the ability to predict events in a continuously changing world $[59,60]$ and repetitive behaviours and interests could represent attempts to regulate uncertainty through sameness and order [59, 60]. Thillay et al., (2016) [61] demonstrated that individuals on the AS cannot flexibly modulate cortical activity according to changing levels of uncertainty. Individuals on the AS were able to extract predictive information and use it to anticipate the predictable targets but over-anticipated stimuli occurring in an uncertain context [61]. This excessive processing may be counterproductive in unpredictable and fluctuating situations, and may lead to stressful reactions, and a sense of being overwhelmed [61]. Neil et al., (2016) [62] investigated the extent to which intolerance of uncertainty' and anxiety, were related to parental reports of sensory sensitivities in children on the AS and in typically developing children. 'Intolerance of uncertainty' explained approximately half the variance in autistic children's sensory sensitivity scores and this relationship was partially mediated by children's anxiety levels. In typically developing children, however, 'intolerance of uncertainty' explained considerably less of the variance of sensory sensitivity. Pellicano and Burr (2012) [60] suggested that individuals on the AS may have difficulties dealing with this uncertainty because they rely less on prior knowledge-due to 
difficulties either constructing internal working models of the world or combining them effectively with sensory signals-leading ultimately to a greater reliance on bottom-up sensory signals and a tendency to perceive the world more accurately. This 'intolerance of uncertainty' could in turn produce attempts to decrease uncertainty, manifesting in anxiety symptoms such as rumination about the possibility of various negative outcomes and an attentional bias to potentially threatening stimuli in the environment [62]. In such a hypervigilant state, individuals could be more likely to notice and respond to aversive sensory stimuli, and less likely to successfully separate from potentially threatening sensory stimuli [63]. More recently, predictive coding framework [64] has been used to help understand information processing in neurodevelopmental disorders [65]. Pellicano and Burr (2012) [60] and Lawson et al. (2014) [66] have proposed that individuals on the AS generate impaired top-down predictions, resulting in failures to contextualize sensory information while others have suggested that these individuals fail in the flexible adjustment of precision [67].

So far, we have presented data on how the attitude of acceptance, enthusiasm and using the child's motivation to encourage learning contributes to social, emotional and cognitive development. When a child feels valued, accepted, encouraged and more in control he is more likely to be responsive and open to experiences and learning. A highly predictable transaction of signaling his needs and having the parent respond quickly, sensitively and positively, provides the child with a sense of control and security which is necessary for the him/her to explore the social world, initiating to the parent as discoveries are made, while receiving continued interest, support and information in return [22]. This aspect highlights the importance of the attitude and behavior of the people that are involved in caring for the child, whether parents, other caregivers or teachers.

\section{ATTITUDE AND THE IMPACT ON BRAIN BIOLOGY}

Several neuroanatomical differences have been associated with the AS and include region-specific volumetric changes (quantified by magnetic resonance imaging), specific alterations in grey or white matter, long-range connectivity of different brain regions (inferred from diffusion tensor imaging) and microstructural or cellular changes detected in postmortem brain tissue [8]. Neuroimaging studies of the AS across childhood, adolescence and adulthood do not typically report structural abnormalities in isolated brain regions, but rather in several large scale neurocognitive systems [68]. Many of the neural structures described as different in the AS, overlap with brain regions which are integral parts of the so-called 'social' and 'emotional' brain, and are involved in wider aspects of social cognition and emotional processing [9]. The components of the neural system underlying the AS include fronto-temporal and fronto-parietal regions; limbic structures such as amygdalahippocampal complex, thalamus and cingulate regions; the fronto-striatal circuitry including parts of the basal ganglia, anterior cingulate cortex and the dorsolateral prefontal cortex; and finally, the cerebellum [9]. However, these neuroanatomical differences are neither unique to, or the cause of, the AS since they are also involved in some psychiatric conditions.

Williams and Minshew (2007) [69] found that individuals on the AS appeared to use different neural circuits to interact socially, work out intention and connection between facial expressions and emotions; appreciate movement, motion and language; and differentiate between automatic and cognitive processing. Other studies have found atypical patterns of connectivity in the prefrontal cortex of individuals on the AS [70], as well as decreased coordination between brain areas [71]. According to Garfinkel et al., (2016) [72] even when marked behavioral deficits are not obvious, adults on the AS manifest characteristic altered patterns of brain activity and neural connectivity during the processing of emotional information, particularly impaired activation [73-75] and impoverished functional connectivity of the insula [76]. Interestingly, the insula maps both bodily and emotional processes in a way accessible to consciousness $[77,78]$ and is considered central to the representation of bodily signals in a manner that informs emotional feelings and behaviors [72, 79].

Gaigg (2012) [7] questions the commonly accepted idea that social-emotional difficulties in the AS are simply a facet of broader social-motivational or socialcognitive impairments. In fact, it could be that the AS is characterized by more general differences in orienting to and processing of relevant stimuli, of which people are merely an example [7]. Specifically, the limbic and striatal regions included in the 'social brain' play a fundamental role in domain-general emotion related processes that alert to biologically relevant events in the environment so that the individual can respond effectively, and learn about what might predict similar future events [7]. 
The amygdala-prefrontal cortex is the main network in emotion regulation. The amygdala is well known for its role in emotion perception, learning and expression. It is critical in the auditory and visual recognition of emotions, specially anger and fear [80], helps regulate threat vigilance [81] and is important in decoding ambiguous emotional information [6, 82]. Although its basic structure is present at birth, the amygdala undergoes significant structural and functional refinement across infancy, childhood and adolescence $[5,83]$, responding very robustly to emotional events in childhood but decreasing its reactivity during adolescence and adulthood [84]. This relative immaturity of the amygdala during childhood suggests its openness to environmental regulation during this stage which has important implications [85]. Further, the prefrontal cortex (PFC) which has been implicated in emotional regulation by exerting a top-down inhibitory control of the amygdala therefore dampening emotional response [6, 86], has a prolonged developmental period in humans and functional connections between the amygdala and PFC are also late in emerging [6].

Callaghan and Tottenham (2016) [6] propose that parents may help regulate the amygdala while the PFC is not yet functionally mature, or that it may be unnecessary to activate this system early on during a time when parents are usually available. The role of parents in the modulation of the amygdala and PFC appears to be critical for circuit tone and for the longterm effectiveness of the circuit in emotion regulation. The same authors [6] propose that the environmental experience of being with a parent acts as a 'neuroscaffold', laying out a blueprint by which stable patterns of neural connectivity are shaped. In this way, the more experience one has with parental modulation of emotion, during the sensitive period of childhood, the greater the modulatory abilities of the circuit later (and the better self-regulatory abilities of the individual). On the other hand, parental absence/unavailability during this stage, or inability of parental presence to buffer the amygdala, may contribute to poor functional/structural circuit connections, with potentially heightened amygdala reactivity and emotionality later on [6].

Several studies have demonstrated that positive parenting can affect brain structure in children. Luby et al., (2012) [87] reported that early maternal support predicted larger hippocampal volumes in school-aged children (7-13 years), especially in non-depressed children. These findings support the idea that early experience of supportive caregiving impacts structural development of the hippocampus [87]. A previous study by Rao et al., (2010) [88] had found that higher quality of parental care early in life predicted smaller hippocampal volumes during early and midadolescence (13-16 years) as well as reduced grey matter in the anterior cingulate cortex and thalamus. Whittle et al., (2014) [89] found that higher frequency of positive maternal behaviour was associated with attenuated growth of the amygdala and accelerated thinning of cortical regions (orbitofrontal and anterior cingulate cortex) from early to mid-adolescence. Accelerated cortical thinning has been associated with increased emotional and behavioural functioning, while attenuated amydala development has been associated with low levels of psychopathology, from early to midadolescence in previous studies [90, 91]. Similarly, Frye et al., (2010) [92], reported that adolescents who experienced consistent responsive mothering during childhood had thinner cortex (globally) than those who experienced inconsistent responsive mothering. Other studies have also shown that negative parenting also affects brain structure in negative way [5, 93]. Sheikh et al., (2014) [94] found associations between white matter microstructure disruptions and cortisol reactivity in important emotion-regulation regions of the limbic system. Positive early parental caregiving moderated the effect of high cortisol reactivity on white matter structure. Specifically, high stress reactive girls who received greater parental positive affect showed white matter structure which was more similar to that of lowstress reactive girls.

Research in parental praise has shown it improves the child's self-esteem, self-efficacy and motivation [95]; promotes attachment [96]; and emotional and physical well-being [97]. Parental praise is a positive expression of social feedback and verbal reward for children and can contribute to a warm environment and promote attachment [96]. It has also been associated with elements of positive parenting such as loving and responsive care, supportiveness, warmth and positive affect [34]. A study by Matsudaira et al., (2016) [34], showed that parental praise was significantly and positively correlated with grey matter volume of the left posterior insular cortex in children. The posterior insula is associated with somatic sensation [98], has an important role in auditory functioning [99] and is linked to interoceptive function via interactions between brain and body [100]. The capacity for interoception, in turn, is correlated with the ability to understand the emotions of others [101] and the posterior insular cortex has also been involved in emotional functioning [34]. As grey 
matter volume in the posterior insular cortex is associated with the recognition of self and others, it is possible that praising a child frequently can facilitate the development of empathy [34]. The posterior insula is functionally connected to the amygdala and this connectivity is associated with emotional regulation [102] which could explain why parental praise correlated significantly and positively to posterior insular volume in the study by Matsudaira et al., (2016) [34].

Data from studies on positive parenting, parental praise and the role of parents in the modulation of the amygdala and PFC provide evidence that brain circuits are sensitive to environmental experiences, emphasizing the importance of the attitude that surrounds the child throughout development. Further, neuroplasticity is not an occasional state of the brain meaning that the ability of the brain to organize itself and gain new skills (through new neural connections) can occur throughout life [12, 13].

Research on peripheral arousal responses shows that individuals on the AS react differently to objects or events that are either ambiguous or variable with respect to their emotional significance. In contrast, responses to clearly defined and invariable emotional signals, are indistinguishable from non-autistic individuals performing the same tests [7]. The amygdala elicits arousal responses and facilitates associative learning besides playing a critical role in orienting attention to emotionally significant stimuli [103]. The mechanisms that regulate peripheral arousal responses operate in parallel to those that regulate attention. At a neural level, this suggests that relatively basic amygdala pathways that mediate the expression of physiological arousal are relatively preserved in individuals on the AS. However, pathways that moderate attention through reciprocal connections with cortical areas, appear to be compromised [7]. As has been referred earlier, and according to Lawson (2013) [37], it is possible that individuals on the AS can widen their attention window due to increased gamma synchrony across neuronal networks that are accessed through motivation. Gamma activity, which is brain wave activity between 30 and $90 \mathrm{~Hz}$, is associated with bursts of insight and high-level processing of information and could enable connection in ways that are not possible outside the motivational interest [37, 104]. In other words, motivation/interest in individuals on the AS awakens attention thus creating a neuropathway to learning [37]. The hypothesis of gamma frequency as a binding frequency that impacts upon event related potentials has been studied by Deco and Thiele (2009) [105] and Rippon et al., (2007) [106] and the idea gamma synchrony can be enhanced by attention/interest has also been explored by Fries (2005) [107].

Individuals on the AS have a different neurobiology and use the brain in different ways to learn and grow. Different doesn't mean less and while some individuals might have outstanding abilities, all are capable of making important progress. Neuroplasticity, the remarkable ability of the brain to form new connections as a result of experience, is not limited to specific parts of the brain nor does it have a time limit, so learning and growth are on-going processes. Thus, one cannot predict what a child will be able to do, or not do, in the future based on current abilities. We have also presented data that shows how attitudes can physically impact neural circuits in the developing brain which highlights the importance of the environment surrounding the child.

\section{CONCLUSION}

In this review we explored the impact of the attitude of acceptance, enthusiasm and learning through motivation on social, emotional and cognitive development, and brain biology in children on the AS. The ability of the brain to reorganize itself and develop new skills by forming new neural connections can take place throughout life but assumes particular importance during childhood development and sensitive periods where environmental stimuli have the potential to shape neural trajectories. Parents assume a critical role in regulating the child's behavior, emotional expression, physiology and stress reactivity. Studies on positive parenting, parental praise and the role of parents in the modulation of the amygdala and PFC provide evidence that brain circuits are sensitive to environmental experiences, emphasizing the importance of the attitude that surrounds the child throughout development. However, the influence of the attitude and behavior of parents and other caregivers in general on the development of children on the AS has not yet received much attention in clinical research. Future research on how specific aspects of parent attitude and/or behavior can impact the development of the child on the AS can contribute to more effective strategies in helping individuals on the AS connect and grow into their full potential. 


\section{ACKNOWLEDGEMENT}

The preparation of this manuscript was undertaken as part of the Autism Children Distance Education Programme, at the Autism Center for Education and Research, School of Education, University of Birmingham. The authors declare that there is no conflict of interests.

\section{FUNDING}

This research received no specific grant from any funding agency in the public, commercial, or not-forprofit sectors.

\section{REFERENCES}

[1] Wing L, Gould J, Gillberg C. Autism spectrum disorders in the DSM-V: Better or worse than the DSM-IV? Research in Developmental Disabilities 2011; 32(2): 768-773. https://doi.org/10.1016/j.ridd.2010.11.003

[2] Bogdashina O. Sensory Perceptual Issues in Autism and Asperger Syndrome: Different Sensory Experiences Different Perceptual Worlds, London, GB: Jessica Kingsley Publishers 2003

[3] Lawson W. The Passionate Mind: How Peolpe with Autism Learn. London: Jessica Kingsley Publishers 2011.

[4] Vivanti G, et al. Predictors of outcomes in autism early intervention: why don't we know more? Front Pediatr 2014; 2: 58.

https://doi.org/10.3389/fped.2014.00058

[5] Tottenham N. The importance of early experiences for neuroaffective development. Curr Top Behav Neurosci 2014; 16: 109-29. https://doi.org/10.1007/978-3-662-45758-0 254

Callaghan BL, Tottenham N. The Neuro-Environmental Loop of Plasticity: A Cross-Species Analysis of Parental Effects on Emotion Circuitry Development Following Typical and Adverse Caregiving. Neuropsychopharmacology 2016; 41(1): 163-76.

https://doi.org/10.1038/npp.2015.204

[7] Gaigg SB. The Interplay between Emotion and Cognition in Autism Spectrum Disorder: Implications for Developmental Theory. Front Integr Neurosci 2012; 6: 113. https://doi.org/10.3389/fnint.2012.00113

[8] Donovan APA, Basson MA. The neuroanatomy of autism - a developmental perspective. Journal of Anatomy 2017; 230(1): 4-15. https://doi.org/10.1111/joa.12542

[9] Ecker C. The neuroanatomy of autism spectrum disorder: An overview of structural neuroimaging findings and their translatability to the clinical setting. Autism 2017; 21(1): 1828.

https://doi.org/10.1177/1362361315627136

[10] Kaufman RK. Autism Breakthrough. USA: St Martin's Press 2014.

[11] Grusec JE, Danyliuk T. Parents' Attitudes and Beliefs: Their Impact on Children's Development, in Encyclopedia on Early Child Development, R.E. Tremblay, Boivin, M., Peters, RDeV, Editor. 2014.

[12] Pascual-Leone $A$, et al. The plastic human brain cortex. Annu Rev Neurosci 2005; 28: 377-401. https://doi.org/10.1146/annurev.neuro.27.070203.144216

[13] Baniel A. Kids Beyond Limits. New York: Penguin Books 2012.
[14] Begley S. Train Your Mind, Change your Brain: How a New Science Reveals Our Extraordinary Potential To Transform Ourselves. New York: Ballantine Books 2007.

[15] Knudsen El. Sensitive periods in the development of the brain and behavior. J Cogn Neurosci 2004; 16(8): 1412-25. https://doi.org/10.1162/0898929042304796

[16] Sorce J, et al. Maternal Emotional Signaling: Its Effect on the Visual Cliff Behavior of One-Year-Olds 1985; Vol. 21: 195200.

[17] Hibel LC, Trumbell JM, Mercado E. Work/non-workday differences in mother, child, and mother-child morning cortisol in a sample of working mothers and their children. Early Hum Dev 2014; 90(1): 1-7. https://doi.org/10.1016/j.earlhumdev.2013.11.007

[18] Gee DG, et al. Maternal buffering of human amygdalaprefrontal circuitry during childhood but not during adolescence. Psychol Sci 2014; 25(11): 2067-78. https://doi.org/10.1177/0956797614550878

[19] Egliston KA, Rapee RM. Inhibition of fear acquisition in toddlers following positive modelling by their mothers. Behav Res Ther 2007; 45(8): 1871-82. https://doi.org/10.1016/j.brat.2007.02.007

[20] Seltzer LJ, et al. Instant messages vs. speech: hormones and why we still need to hear each other. Evol Hum Behav 2012; 33(1): 42-45

https://doi.org/10.1016/j.evolhumbehav.2011.05.004

[21] Mesurado B, Richaud M. Children's perception of parental relationship and personality traits in Argentinean children, in Personality Traits: Causes, Conceptions and Consequences, M.A.W. E. E. Crossman, Editor. New York 2013; pp. 1-26.

[22] Warren SF, Brady NC. The role of maternal responsivity in the development of children with intellectual disabilities. Ment Retard Dev Disabil Res Rev 2007; 13(4): 330-8. https://doi.org/10.1002/mrdd.20177

[23] Spiker D, Boyce GC, Boyce LK. Parent-child interactions when young children have disabilities, in International Review of Research in Mental Retardation. Academic Press. 2002; pp. 35-70. https://doi.org/10.1016/S0074-7750(02)80005-2

[24] Patterson SY, et al. The association between parental interaction style and children's joint engagement in families with toddlers with autism. Autism 2014; 18(5): 511-8. https://doi.org/10.1177/1362361313483595

[25] Trivette CM. Influence of caregiver responsiveness on the development of young children with or at risk for developmental disabilities. Bridges 2003; 1(3): 1-13.

[26] Mahoney G, Perales F. Relationship-focused early intervention with children with pervasive developmental disorders and other disabilities: a comparative study. J Dev Behav Pediatr 2005; 26(2): 77-85. https://doi.org/10.1097/00004703-200504000-00002

[27] Kim J-M, Mahoney G. The Effects of Mother's Style of Interaction on Children's Engagement. Topics in Early Childhood Special Education 2004; 24(1): 31-38. https://doi.org/10.1177/02711214040240010301

[28] Siller M, Sigman M. The behaviors of parents of children with autism predict the subsequent development of their children's communication. J Autism Dev Disord 2002; 32(2): 77-89. https://doi.org/10.1023/A:1014884404276

[29] Lewis M, Goldberg S. Perceptual-cognitive development in infancy: a generalized expectancy model as a function of the mother-infant interaction. ETS Research Bulletin Series 1968; 1968(2): i-43. https://doi.org/10.1002/j.2333-8504.1968.tb00568.x

[30] Bugental D, Brown M, Reiss C. Cognitive Representations of Power in Caregiving Relationships: Biasing Effects on Interpersonal Interaction and Information Processing. Journal of Family Psychology 1996; 10: 397-407. https://doi.org/10.1037/0893-3200.10.4.397 
[31] Vinik J, Almas A, Grusec J. Mothers' Knowledge of What Distresses and What Comforts Their Children Predicts Children's Coping, Empathy, and Prosocial Behavior. Parenting 2011; 11(1): 56-71.

https://doi.org/10.1080/15295192.2011.539508

[32] Hastings P, Grusec JE. Conflict Outcome as a Function of Parental Accuracy in Perceiving Child Cognitions and Affect. Social Development 1997; 6(1): 76-90. https://doi.org/10.1111/j.1467-9507.1997.tb00095.x

[33] Murphy BK, Miller KD. Balanced Amplification: A New Mechanism of Selective Amplification of Neural Activity Patterns. Neuron 2009; 61(4): 635-648. https://doi.org/10.1016/j.neuron.2009.02.005

[34] Matsudaira I, et al. Parental Praise Correlates with Posterior Insular Cortex Gray Matter Volume in Children and Adolescents. PLoS One 2016; 11(4): e0154220. https://doi.org/10.1371/journal.pone.0154220

[35] LeDoux J. Synaptic Self: How Our Brains Become Who We Are. New York: Viking/Penguin 2002.

[36] Lewis MD. Self-organizing individual differences in brain development. Developmental Review 2005; 25(3): 252-277. https://doi.org/10.1016/j.dr.2005.10.006

[37] Lawson W. Sensory connection, interest/attention and gamma synchrony in autism or autism, brain connections and preoccupation. Med Hypotheses 2013; 80(3): 284-8. https://doi.org/10.1016/j.mehy.2012.12.005

[38] Prizant BM. Uniquely Human: A Different Way of Seeing Autism. USA: Simon \& Schuster, Inc. 2015.

[39] Lawson W. Concepts of Normality: The Autistic and Typical spectrum. London: Jessica kingsley Publishers 2008.

[40] Murray D, Lesser M, Lawson W. Attention, monotropism and the diagnostic criteria for autism. Autism 2005; 9(2): 139-56. https://doi.org/10.1177/1362361305051398

[41] Kluth P. You're Going to Love This Kid: Teaching Students with Autism in the Inclusive Classroom, Baltimore: Paul H. Brooks 2003.

[42] Gernsbacher MA, Stevenson JL, Khandakar S, Goldsmith $\mathrm{HH}$. Why does joint attention look atypical in autism? Child Development Perspectives 2008; 2: 38-45. https://doi.org/10.1111/j.1750-8606.2008.00039.x

[43] Kluth P, Chandler-Olcott K. A Land We Can Share: Teaching Literacy to Students with Autism. Baltimore: Paul H. Brooks 2008.

[44] Vismara LA, Lyons GL. Joint attention behaviours in young children with autism: Theoretical and clinical implications for understanding motivation. Jornal of Positive Behaviour Interventions 2007; 9(4): 214-228. https://doi.org/10.1177/10983007070090040401

[45] Lawson W. Learning styles: single attention and associated cognition in autism (SAACA) M. Faculty of Health, Nursing and Behavioural Sciences \& Deakin University. School of Psychology. Editor. 2009.

[46] Premack D, Woodruff G. Does the chimpanzee have a theory of mind? Behavioral and Brain Sciences 1978; 1(4): 515-526.

https://doi.org/10.1017/S0140525X00076512

[47] Baron-Cohen S, Leslie AM, Frith U. Does the autistic child have a "theory of mind"? Cognition 1985; 21(1): 37-46. https://doi.org/10.1016/0010-0277(85)90022-8

[48] Lawson W. Autism. LAP Lambert Academic Publishing 2011.

[49] Baron-Cohen S. The extreme male brain theory of autism. Trends Cogn Sci 2002; 6(6): 248-254. https://doi.org/10.1016/S1364-6613(02)01904-6

[50] Bowler DM. Autism: Specific Cognitive Deficit or Emergent End-point of Multiple Interacting Systems? in The Development of Autism: perspectives from Theory and Research, T.C. J. A. Burack, T. N. Yirmiya, P. R. Zelazo, Editor. Lawrence Erlbaum: Mahwah, NJ. 2001; pp. 219-235.
[51]

Dahlgren SO, Trillingsgaard A. Theory of mind in nonretarded children with autism and Asperger's syndrome. A research note. J Child Psychol Psychiatry 1996; 37(6): 75963.

https://doi.org/10.1111/j.1469-7610.1996.tb01469.x

[52] McAlister A, Peterson C. A longitudinal study of child siblings and theory of mind development. Cognitive Development 2007; 22(2): 258-270. https://doi.org/10.1016/j.cogdev.2006.10.009

[53] Hill EL. Evaluating the theory of executive dysfunction in autism. Developmental Review 2004; 244: 189-233. https://doi.org/10.1016/j.dr.2004.01.001

[54] Ozonoff $\mathrm{S}$, et al. Executive function abilities in autism and Tourette syndrome: an information processing approach. J Child Psychol Psychiatry 1994; 35(6): 1015-32. https://doi.org/10.1111/j.1469-7610.1994.tb01807.x

[55] Robins B, Dickerson P, Stribling P, Dautenhahn K. Robotmediated joint attention in children with autism: A case study in robot-human interaction. Interaction Studies 2004; 5(2): 161-198.

https://doi.org/10.1075/is.5.2.02rob

[56] Frith U, Happe F. Autism: beyond "theory of mind". Cognition 1994; 50(1-3): 115-32. https://doi.org/10.1016/0010-0277(94)90024-8

[57] Mottron L, et al. Enhanced perceptual functioning in autism: an update, and eight principles of autistic perception. $J$ Autism Dev Disord 2006; 36(1): 27-43 https://doi.org/10.1007/s10803-005-0040-7

[58] Blakemore SJ, Choudhury S. Development of the adolescent brain: implications for executive function and social cognition. J Child Psychol Psychiatry 2006; 47(3-4): 296-312. https://doi.org/10.1111/j.1469-7610.2006.01611.x

[59] Gomot M, Wicker B. A challenging, unpredictable world for people with autism spectrum disorder. Int J Psychophysiol 2012; 83(2): 240-7. https://doi.org/10.1016/j.ijpsycho.2011.09.017

[60] Pellicano E, Burr D. When the world becomes 'too real': a Bayesian explanation of autistic perception. Trends Cogn Sci 2012; 16(10): 504-10.

https://doi.org/10.1016/..tics.2012.08.009

[61] Thillay A, et al. Atypical Brain Mechanisms of Prediction According to Uncertainty in Autism. Frontiers in Neuroscience 2016; 10: 317. https://doi.org/10.3389/fnins.2016.00317

[62] Neil L, Olsson NC, Pellicano E. The Relationship Between Intolerance of Uncertainty, Sensory Sensitivities, and Anxiety in Autistic and Typically Developing Children. Journal of Autism and Developmental Disorders 2016; 46: 1962-1973. https://doi.org/10.1007/s10803-016-2721-9

[63] Green SA, Ben-Sasson A. Anxiety disorders and sensory over-responsivity in children with autism spectrum disorders: is there a causal relationship? J Autism Dev Disord 2010; 40(12): 1495-504.

https://doi.org/10.1007/s10803-010-1007-x

[64] Friston $K$. The free-energy principle: a rough guide to the brain? Trends Cogn Sci 2009; 13(7): 293-301. https://doi.org/10.1016/j.tics.2009.04.005

[65] Gonzalez-Gadea ML, et al. Predictive coding in autism spectrum disorder and attention deficit hyperactivity disorder. Journal of Neurophysiology 2015; 114(5): 2625-2636. https://doi.org/10.1152/jn.00543.2015

[66] Lawson RP, Rees G, Friston KJ. An aberrant precision account of autism. Front Hum Neurosci 2014; 8: 302. https://doi.org/10.3389/fnhum.2014.00302

[67] Van de Cruys S, et al. Precise minds in uncertain worlds: predictive coding in autism. Psychol Rev 2014; 121(4): 64975.

https://doi.org/10.1037/a0037665 
[68] Ecker C, et al. Brain surface anatomy in adults with autism: the relationship between surface area, cortical thickness, and autistic symptoms. JAMA Psychiatry 2013; 70(1): 59-70. https://doi.org/10.1001/jamapsychiatry.2013.265

[69] Williams DL, Minshew NJ. Understanding autism and related disorders: what has imaging taught us? Neuroimaging Clin $\mathrm{N}$ Am 2007; 17(4): 495-509, ix.

https://doi.org/10.1016/j.nic.2007.07.007

[70] Wicker B, et al. Abnormal cerebral effective connectivity during explicit emotional processing in adults with autism spectrum disorder. Social Cognitive and Affective Neuroscience 2008; 3(2): 135-143. https://doi.org/10.1093/scan/nsn007

[71] Hadjikhani $\mathrm{N}$, et al. Abnormal activation of the social brain during face perception in autism. Hum Brain Mapp 2007; 28(5): 441-9.

https://doi.org/10.1002/hbm.20283

[72] Garfinkel SN, et al. Discrepancies between dimensions of interoception in autism: Implications for emotion and anxiety. Biological Psychology 2016; 114: 117-126. https://doi.org/10.1016/j.biopsycho.2015.12.003

[73] Duerden EG, et al. Neural correlates of inhibition of socially relevant stimuli in adults with autism spectrum disorder. Brain Research 2013; 1533: 80-90.

https://doi.org/10.1016/j.brainres.2013.08.021

[74] Hadjikhani $\mathrm{N}$, et al. Body expressions of emotion do not trigger fear contagion in autism spectrum disorder. Social Cognitive and Affective Neuroscience 2009; 4(1): 70-78. https://doi.org/10.1093/scan/nsn038

[75] Watanabe $\mathrm{T}$, et al. Diminished medial prefrontal activity behind autistic social judgments of incongruent information. PLoS One 2012; 7(6): e39561.

[76] Ebisch $\mathrm{SJH}$, et al. Altered intrinsic functional connectivity of anterior and posterior insula regions in high-functioning participants with autism spectrum disorder. Human Brain Mapping 2011; 32(7): 1013-1028. https://doi.org/10.1002/hbm.21085

[77] Terasawa $\mathrm{Y}$, et al. Anterior insular cortex mediates bodily sensibility and social anxiety. Social Cognitive and Affective Neuroscience 2013; 8(3): 259-266. https://doi.org/10.1093/scan/nss 108

[78] Zaki J, Davis JI, Ochsner KN. Overlapping activity in anterior insula during interoception and emotional experience. Neurolmage 2012; 62(1): 493-499. https://doi.org/10.1016/j.neuroimage.2012.05.012

[79] Craig AD. How do you feel? an interoceptive moment with your neurobiological self. New Jersey: Princeton University Press 2015.

[80] Adolphs $\mathrm{R}$, et al. A mechanism for impaired fear recognition after amygdala damage. Nature 2005; 433(7021): 68-72. https://doi.org/10.1038/nature03086

[81] Terburg $D$, et al. Hypervigilance for fear after basolateral amygdala damage in humans. Translational Psychiatry 2012; 2(5): e115.

[82] de Gelder B, et al. The role of human basolateral amygdala in ambiguous social threat perception. Cortex 2014; 52: 28-34. https://doi.org/10.1016/j.cortex.2013.12.010

[83] Tottenham N, Sheridan MA. A review of adversity, the amygdala and the hippocampus: a consideration of developmental timing. Front Hum Neurosci 2009; 3: 68. https://doi.org/10.3389/neuro.09.068.2009

[84] Gee DG, et al. A developmental shift from positive to negative connectivity in human amygdala-prefrontal circuitry. J Neurosci 2013; 33(10): 4584-93. https://doi.org/10.1523/JNEUROSCI.3446-12.2013

[85] Lupien SJ, et al. Effects of stress throughout the lifespan on the brain, behaviour and cognition. Nat Rev Neurosci 2009; 10(6): 434-45.

https://doi.org/10.1038/nrn2639
[86] Milad MR, et al. Fear extinction in rats: implications for human brain imaging and anxiety disorders. Biol Psychol 2006; 73(1): 61-71. https://doi.org/10.1016/j.biopsycho.2006.01.008

[87] Luby JL, et al. Maternal support in early childhood predicts larger hippocampal volumes at school age. Proc Natl Acad Sci USA 2012; 109(8): 2854-9.

https://doi.org/10.1073/pnas.1118003109

[88] Rao $\mathrm{H}$, et al. Early parental care is important for hippocampal maturation: evidence from brain morphology in humans. Neuroimage 2010; 49(1): 1144-50. https://doi.org/10.1016/j.neuroimage.2009.07.003

[89] Whittle S, et al. Positive parenting predicts the development of adolescent brain structure: a longitudinal study. Dev Cogn Neurosci 2014; 8: 7-17. https://doi.org/10.1016/j.den.2013.10.006

[90] Ducharme $\mathrm{S}$, et al. Anxious/depressed symptoms are linked to right ventromedial prefrontal cortical thickness maturation in healthy children and young adults. Cereb Cortex 2014; 24(11): 2941-50. https://doi.org/10.1093/cercor/bht151

[91] Shaw $P$, et al. Intellectual ability and cortical development in children and adolescents. Nature 2006; 440(7084): 676-9. https://doi.org/10.1038/nature04513

[92] Frye RE, et al. Preterm birth and maternal responsiveness during childhood are associated with brain morphology in adolescence. J Int Neuropsychol Soc 2010; 16(5): 784-94. https://doi.org/10.1017/S1355617710000585

[93] Shinohara $\mathrm{R}$, et al. The trajectory of children's social competence from 18 months to 30 months of age and their mother's attitude towards the praise. J Epidemiol 2010; 20(Suppl 2): S441-6. https://doi.org/10.2188/jea.JE20090221

[94] Sheikh $\mathrm{HI}$, et al. Links between white matter microstructure and cortisol reactivity to stress in early childhood: evidence for moderation by parenting. Neuroimage Clin 2014; 6: 7785

https://doi.org/10.1016/j.nicl.2014.08.013

[95] Brummelman $\mathrm{E}$, et al. On feeding those hungry for praise: person praise backfires in children with low self-esteem. $J$ Exp Psychol Gen 2014; 143(1): 9-14. https://doi.org/10.1037/a0031917

[96] Owen DJ, Slep AM, Heyman RE. The effect of praise, positive nonverbal response, reprimand, and negative nonverbal response on child compliance: a systematic review. Clin Child Fam Psychol Rev 2012; 15(4): 364-85. https://doi.org/10.1007/s10567-012-0120-0

[97] Polcari A, et al. Parental verbal affection and verbal aggression in childhood differentially influence psychiatric symptoms and wellbeing in young adulthood. Child Abuse Negl 2014; 38(1): 91-102. https://doi.org/10.1016/j.chiabu.2013.10.003

[98] Nagai M. Structure and functions of the insular cortex-A review of the recent researches. Advances in Neurological Sciences 2002; 46(1; ISSU 242): 157-173.

[99] Bamiou DE, Musiek FE, Luxon LM. The insula (Island of Reil) and its role in auditory processing. Literature review. Brain Res Brain Res Rev 2003; 42(2): 143-54 https://doi.org/10.1016/S0165-0173(03)00172-3

[100] Ohira $\mathrm{H}$. [Functions of the insula and sense of self]. Brain Nerve 2014; 66(4): 417-27.

[101] Terasawa $Y$, et al. Interoceptive sensitivity predicts sensitivity to the emotions of others. Cogn Emot 2014; 28(8): 1435-48. https://doi.org/10.1080/02699931.2014.888988

[102] Denny BT, et al. Insula-amygdala functional connectivity is correlated with habituation to repeated negative images. Soc Cogn Affect Neurosci 2014; 9(11): 1660-7. https://doi.org/10.1093/scan/nst160 
[103] Vuilleumier $P$. The role of the human amygdala in perception and attention, in The Human Amygdala, P.J. Whalen, Phelps, E. A., Editor. The Guilford Press: New York 2009.

[104] Wenn L. Autism spectrum conditions: the pathophysiological basis for inattention and the new Diagnostic and Statistical Manual of Mental Disorders (DSM-V). OA Autism 2013 Mar 01;1(1):1. OA Autism 2013; 1(1): 1.

[105] Deco G, and A. Thiele, Attention: oscillations and neuropharmacology. Eur J Neurosci 2009; 30(3): 347-54. https://doi.org/10.1111/j.1460-9568.2009.06833.x
[106] Rippon G, et al. Disordered connectivity in the autistic brain: challenges for the "new psychophysiology". Int J Psychophysiol 2007; 63(2): 164-72. https://doi.org/10.1016/j.ijpsycho.2006.03.012

[107] Fries P. A mechanism for cognitive dynamics: neuronal communication through neuronal coherence. Trends Cogn Sci 2005; 9(10): 474-80. https://doi.org/10.1016/j.tics.2005.08.011

DOI: https://doi.org/10.6000/2292-2598.2018.06.01.3

(C) 2018 Prata et al.; Licensee Lifescience Global.

This is an open access article licensed under the terms of the Creative Commons Attribution Non-Commercial License (http://creativecommons.org/licenses/by-nc/3.0/) which permits unrestricted, non-commercial use, distribution and reproduction in any medium, provided the work is properly cited. 